\title{
Personalized Learning Strategy as a Tool to Improve Academic Performance and Motivation of Students
}

\author{
Aliya Makhambetova, Abai Kazakh National University, Kazakhstan \\ Nadezhda Zhiyenbayeva, Abai Kazakh National Pedagogical University, Kazakhstan \\ Elena Ergesheva, I. M. Sechenov First Moscow State Medical University (Sechenov University), Russia
}

\begin{abstract}
The purpose of the research is to study and scientifically substantiate personalized strategies as the basis for personalized learning aimed at improving academic performance and student motivation. The study involved 65 teachers and 700 students of various specialties from three Russian and Kazakhstan universities. The survey analysis showed that the modern generation of students is no longer motivated to receive standardized educational services, and in this context, personalized strategies as a form of personalized learning are a key trend that has permeated all aspects of professional training. Unfortunately, currently, universities find it difficult to implement such an approach as personalized learning makes educational modules highly adapted and individualized to meet the needs of each particular student. To apply personalized strategies in the educational process, it is necessary to study the structure of a particular institution, to analyze educational programs, to conduct classes based on personalized learning strategies.
\end{abstract}

\section{KEYWORDS}

Academic Self-Esteem, Achievement Motivation, Individual Dual-Oriented Learning Pathway, Personalized Learning Strategy, Student-Centered Learning

\section{INTRODUCTION}

Modern higher education has great potential for the use of various strategies for personalized and adaptive learning to improve the university teaching system (Rodríguez-Triana et al., 2015). Strategy is a term that is used in various spheres of human activity and does not have a common and comprehensive interpretation. Strategy is an action that managers take to achieve the goals of the organization. Strategy can also be defined as the general direction set for the achievement of the desired state in the future. Strategy is the result of careful strategic planning (Felder \& Silverman, 1988). Most importantly, strategy is a determining factor in the success of any human activity.

\section{Learning Strategies Dissemination And Differentiation}

Learning strategies were singled out as a separate research direction in the mid-1980s, which showed the importance of a conscious attitude to the learning process and learning actions. J. Rubin was one of the first to introduce the concept of strategy in the context of learning. J. Rubin defines learning strategies as techniques that students can use to master knowledge (Witkin et al., 1962). Learning strategies are considered as actions and mental effort that the learner takes in order to expand the

\section{DOI: 10.4018/IJWLTT.286743}

This article published as an Open Access article distributed under the terms of the Creative Commons Attribution License (http://creativecommons.org/licenses/by/4.0/) which permits unrestricted use, distribution, and production in any medium, provided the author of the original work and original publication source are properly credited. 
perception of the instructional material (Cohen, 2011); there are three categories of learning strategies (Witkin et al., 1962):

- metacognitive strategies that are used by the learner to plan, organize and control their learning activities, as well as to analyze achievements;

- cognitive strategies are conscious techniques for organizing the learning process; for example, taking notes, selecting scientific sources (using dictionaries and other resources), repetition for better memorization, drawing analogies, memorizing terms, key concepts;

- $\quad$ socially affective strategies involve learning through interaction, exchange of information; for example, working with other students, solving a common problem, consulting a teacher.

Learning strategies are individual approaches that students use to complete educational tasks and improve their skills. Strategic learning contributes to the fact that students become more independent participants in the educational process who can also apply certain strategies in future professional activities (Malykhin \& Galla, 2016). A personalized learning approach increases student motivation and engagement, which improves academic performance. Personalized learning is a solution for adapting education to the needs of people and their previous experience (Lee et al., 2018; Miliband, 2006) that allows everyone to reach their fullest potential through personalized learning (Hsieh \& Chen, 2016; Lin et al., 2013). In turn, personalized learning strategies have several synonyms, namely personalized learning, individual developmental trajectory, individual learning pathway.

The term adaptive learning is often used synonymously with the concept of personalized learning. Today, adaptive learning is a developed system ( $\mathrm{Lu}$ et al., 2014) that allows taking into account a number of individual differences (Scheiter et al., 2019; Wang \& Liao, 2011), such as gender, learning motivation, cognitive type and learning style, in order to determine the most suitable adaptive learning experience with due regard to various individual differences (Afini Normadhi et al., 2019), as well as to remove time and geographic barriers.

Individual learning pathway is one of the terms that are often used to refer to the specific needs and goals of people that need to be addressed in the learning process. It is like a portal that offers customized educational content based on the cognitive knowledge of a learner (Bahçeci \& Gürol, 2016). The learning process should take into account the individual differences of learners, such as student learning styles and characteristics (Bahçeci \& Gürol, 2016; Shemshack \& Spector, 2020). So far, more than 70 models of learning styles have been documented (Coffield et al., 2004). The concept of learning style is used to refer to the preferred individual way of collecting, organizing, and processing information (Hernández-Torrano et al., 2017). This term has been especially popular over the past decades; it is based on the belief that the knowledge of the preferred learning style as well as the preferred learning approach can be useful in informing the student about how they can adapt and improve to enhance learning (Chan et al., 2011; Samarakoon et al., 2013). In the field of medical education, one of the most common learning style models is the Felder-Silverman model (Felder \& Silverman, 1988). The model highlights four learning style dimentions: sensing and intuitive Learners; visual and verbal learners; active and reflective learners; sequential and global learners (Hernández-Torrano et al., 2017).

\section{Personalized Learning Concept}

Personalized learning is defined as a student-centered system that supports their diverse needs and the development of abilities (Lee et al., 2018). The system develops personalized learning methods and educational content for students with unique characteristics and interests. Dual-oriented learning is becoming relevant in the context of increasing creativity, social significance, and cultural value of the result, thereby contributing to the self-organization of the cognitive activity system, goal setting, and the change of semantic attitudes. An individual dual-oriented learning pathway is ensured through the 
integration of educational, applied, and professional activities of students and is designed to stimulate professional and pedagogical, personal self-determination and self-development of students.

Personalized learning is an integrated approach to activities that are the product of selforganization (Chatti et al., 2010) or learning, or the individual instruction that takes into account personal needs and goals. Personalized learning is considered as an effective approach, which can increase student motivation, engagement and awareness (Pontual Falcão et al., 2018), as well as maximize learner satisfaction and learning effectiveness (Gómez et al., 2014). Personalization as the basis of student-centered learning implies a high degree of student involvement shifting the focus of responsibility and expectations towards the strengths and weaknesses of each student in order to create content that can meet those needs. Personalized learning should entail the development of methodological and organizational support, as well as a change in the role of the teacher. Students need psychological and pedagogical support to succeed in personalized learning; it has been found that the emotional and psychological support of teachers is an important factor in the academic success of students (Tapalova et al., 2018). A personalized strategy is aimed at improving reflexivity, autonomy, motivational focus, personal and social responsibility, and critical ability of modern students. It can be viewed as a holistic strategy that includes a large number of various educational practices aimed at teaching students taking into account their strengths and weaknesses (Hachfeld \& Lazarides, 2020; Tapalova, 2014).

The second significant method for solving the problem of personalized and adaptive learning is formed through learning with the help of artificial intelligence. Intelligent tutoring systems have been developing for about fifteen years and have hundreds of specialized applications, approaches and already practically proven methods (Mousavinasab et al., 2018). The framework of intelligent tutoring systems includes a thorough study of the learning user, his individual psychological and cognitive characteristics, which allows not only to optimally distribute the teaching material and select teaching methods, but also to create stronger involvement and motivation for each individual user of such a system (Morgan et al., 2020; Yang \& Zhang, 2019). Artificial Intelligence can also generate Multiple Representations of training information, making it easy to access training from whatever platform is optimal for the user.

\section{Affecting Students' Performance Factors}

The identification of factors affecting the academic performance of students has always been one of the most important tasks of researchers and educational psychologists (Mega et al., 2014), as well as one of the challenges faced by medical universities (Artino et al., 2010; Sagheb et al., 2018). To this end, researchers have focused on recognizing the role of motivation, learning strategies, and academic emotions in learning and student achievement (Hayat et al., 2020; Ngwira et al., 2017).

Motivation is a multifaceted concept that is considered in several disciplines as it is defined as the driving force behind human actions and is not obvious from the outside. Placing the focus on the cognitive approach, motivation is defined as the process that stimulates and supports purposeful activity (Schumacher \& Ifenthaler, 2018). Motivational factors such as interest, autonomy, competence, family and self-efficacy determine the regulatory efforts of students to achieve the learning goal (Eseryel et al., 2014). In a self-regulated learning environment, such as higher education or online learning, motivation is critical to successful learning (Moos \& Bonde, 2016). It is believed that self-regulating learning processes are interrelated to motivational processes as motivation affects the choice of learning strategy, learning processes, and outcomes. Similarly, self-regulation can influence student motivation (Lehmann et al., 2014).

Academic self-esteem describes the cognitive representation of the perceived abilities of a person in the context of academic achievement. As for learning outcomes, it is important that intrinsic motivation relates to learners' perceived competence and can be supported by skill selection, as well as challenging tasks and feedback postulating a causal influence of the academic self-concept on intrinsic motivation. Academic self-efficacy refers to students' beliefs and attitudes towards their 
ability to achieve academic success, as well as the belief in their ability to accomplish academic tasks and study the material successfully (Hayat et al., 2020). Students with high self-efficacy associate their failure with fewer attempts rather than lower ability, while students with low self-efficacy attribute their failures to their poor abilities. The studies involving 214 psychology students from Saudi Arabian universities have shown that academic self-efficacy has a positive and significant effect on their academic performance (Alyami, 2017). In addition, academic self-efficacy has a significant impact on student learning, motivation, and academic performance as evidenced by a number of scientific studies.

The ARCS (Attention, Relevance, Confidence, Satisfaction) model aims to integrate and thus illustrate the relationship between the theoretical concepts of will, motivation, learning, and performance to facilitate research and instructional design to create a motivating (online) learning environment. The model includes four components: (1) attention related to the level of curiosity; (2) relevance of the learning objective to the learner, including its perceived value; (3) confidence in the success of the learning activity, including the attribution of the learning outcome, and (4) satisfaction with the assessed quality of the learning outcome and the learning process. These four components are complemented by will, which includes self-regulation strategies to maintain purposeful behavior (Schumacher \& Ifenthaler, 2018).

Psychologically, motivation to learn is described as the student's energy and aspiration to learn, work efficiently, and fulfill their potential along with the behavior associated with those intentions. It should be highlighted that the curriculum of higher education used to be based primarily on cognitive approaches rather than the theory of motivation; therefore, motivation to learn is still underestimated. The Association for Medical Education in Europe guidance on Motivation in Medical Education notes that medical students should be motivated in connection to the fact that they receive highly specialized education. Motivation is a major determinant of the quality and success of learning, the lack of which may well explain why there are disaffected, discouraged, or dropping out medical students. Therefore, it is very important to know what drives students to learn, as well as the methods that can guide teachers to help them choose teaching approaches and ultimately influence student outcomes, including their retention in the institution (Edgar et al., 2019).

\section{Research Question And Problem Statement}

Contrary to the opinion widely held by many empirical academic studies, personalization of learning does not necessarily meet with support and positive perception in the educational systems of developing countries (Afini Normadhi et al., 2019; Erstad \& Voogt, 2018; Hsieh \& Chen, 2016). Personalization requires more technical equipment, sophisticated pedagogical skills and specialized teacher training, which can be problematic. We believe the contribution of this study is to assess the real motivation and attitude towards the personalization process on both sides, both teachers and students at the same time, and to highlight the optimal points and methods of interaction supported by both sides. This kind of research, as far as it is possible to estimate, has not been conducted before, and they are very significant in the context of educational processes in developing countries.

There is a debate in academia about whether personalization and learning quality are related or interdependent. While some researchers include personalization into the practical implementation of the quality of learning, others believe that the quality of learning mediates between personalization and learning outcomes. This is complicated by the fact that both personalization and the quality of learning are multidimensional constructs. The present paper considers personalization as an educational interaction focused on student interests, activity, and initiative, as well as the reflective position of the teacher. Therefore, there may be a different relationship between the behavioral components of personalization, the orientations and sub-aspects of the quality of learning due to the Small number of studies devoted to the issue (Hachfeld \& Lazarides, 2020). Our analysis was based on the assumptions that personalized learning strategies in modern vocational education play a huge role as they affect academic performance and student motivation. The novelty and contribution of this 
Table 1. Respondents University teachers

\begin{tabular}{|l|l|}
\hline \multicolumn{1}{|c|}{ Educational institution } & \multicolumn{1}{c|}{ Number of respondents } \\
\hline xxxx University & 33 \\
Kazakhstan & 32 \\
Total & 65 \\
\hline
\end{tabular}

study lies in the broad analysis of the motivational factors formed by the use of personalized learning and, at the same time, the study of the point of view of teachers on the use of these methods. This counter-methodology allows us to highlight the moments in the implementation of personalization learning methods that are most conducive to increasing the academic effectiveness of teaching and student engagement. In this regard, the following research objectives have been identified:

- $\quad$ to highlight personalized learning strategies in vocational education;

- to survey students and teachers to find out the ways personalized learning strategies are applied in higher educational institutions and determine their effect on academic performance and student motivation;

- $\quad$ based on the results obtained, to find possible solutions to apply personalized learning strategies to increase academic performance and student motivation.

\section{MATERIAL AND METHODS}

\section{Research Design}

Based on the research objectives, an empirical study, which included a questionnaire survey of students and teachers, was conducted in order to collect research data. The study relied on the quantitative research methodology to collect and analyze the interpretations and values of the survey.

\section{Table 2. Respondents University students}

\begin{tabular}{|l|l|}
\hline \multicolumn{1}{|c|}{ Educational institution } & \multicolumn{1}{c|}{ Number of respondents } \\
\hline xxxx University & 380 \\
Kazakhstan & 320 \\
Total & 700 \\
\hline
\end{tabular}

\section{Participants}

University teachers were surveyed in order to assess their attitudes towards personalized learning strategies in vocational education. There were 65 teachers of Russian and Kazakhstan medical and pedagogical universities participating in the study. The average age of the respondents was 43.2 years (Table 1). Before the experiment, the teachers signed their consent to take part in the study.

The study also involved 700 students aged 18-19. Among them, there were $63 \%$ of women and $37 \%$ of men. The student sample consisted of intramural students (Table 2) and according to the results of previous examinations, all students were good achievers.

In order to expand the scope of the study given the questionnaire limitations, the survey involved first and fourth-year students. 


\section{Participant Selection Criteria}

First and fourth-year students were selected to expand the scope of the study. In addition, students of various specialties, including Medicine (General Medicine), Mechanics and Mathematical Modeling, Biotechnology, Information Systems and Technologies, Nanomaterials, Dentistry, Pharmacy, Bioengineering and Bioinformatics, Defectology (5B010500), Pedagogy and Psychology, were surveyed. This made it possible to more thoroughly assess the use of personalized learning strategies in the learning environment to improve academic performance and increase student motivation.

The survey involved both teachers and students due to the fact that their attitude to the issue of personalized learning strategies as a tool to improve academic performance and motivation to learn may be different. This will allow the assessment of the situation from the perspective of both teachers and students.

\section{Research Limitations}

The study involved only students and teachers from the universities mentioned above. First xxxx University is an advanced research, educational and clinical center in the healthcare system of Russia, as well as the Kazakhstan university, where innovations in the educational process are most likely. This information does not allow us to judge the situation in provincial educational institutions. In addition, the data obtained as a result of the quantitative analysis can be quite general. This study presents a detailed analysis of descriptive statistics to create the most detailed representation of the phenomenon under study; more accurate statistical analysis becomes possible in subsequent works.

\section{Research Tools}

There were two surveys in the study. The first survey was conducted among students and included two questionnaires. The first questionnaire aimed to study the motivation for educational activity (the methodology developed by A. Rean and V. A. A. Yakunin aimed at studying the motives for the educational activity of students" (Ilyin, 2011). The survey was conducted based on the methodology by I. Ilyin (Motivation to study at university) and the methods by T. Ehlers (n.d.) "Motivation to succeed and Motivation to avoid failures". The second questionnaire consisted of eight questions and asked students to choose a positive or negative answer reflecting their views on personalized learning strategies in vocational education (see Figure 1).

The second part of the study involved teachers. The survey described the most common personalized learning strategies in vocational education. The participants were asked to select the most common and effective ones. More than one option was possible (Table 3).

The teachers were provided with eight questions to choose from that could be associated with both vocational and higher education. The questions contain tendencies related to various aspects: personal, informational, and educational. The data obtained based on the survey will help us assess which trends in vocational education educators consider to be the most important.

\section{Data Analysis}

After the survey, the analysis of the research data was carried out based on mathematical and statistical processing performed in Microsoft Excel.

The error is 4\%; about 28 questionnaires were not properly filled in (some respondents did not answer all the questions or chose more than one answer option). When analyzing each answer (answer option), the number of respondents who chose it was calculated. Next, at the stage of the result calculation, the data were turned into a percentage calculated from the total number of respondents for each item. 
Table 3. Teacher survey

\begin{tabular}{|l|l|}
\hline \multicolumn{1}{|c|}{ Personalized learning strategies } & \multicolumn{1}{c|}{ Answer description } \\
\hline Teaching students to focus on the result & In higher education, students are taught to achieve real results. \\
\hline Mentoring & The teacher also acts as an assistant, that is, guides the student. \\
\hline $\begin{array}{l}\text { Impossibility of knowledge transfer without } \\
\text { training }\end{array}$ & $\begin{array}{l}\text { The teacher develops students' professional skills based on the } \\
\text { knowledge they assimilate. }\end{array}$ \\
\hline Education quality support programs & $\begin{array}{l}\text { Providing teachers and students with the information they need } \\
\text { (e.g. special programs, curriculum, etc.) }\end{array}$ \\
\hline Problem-based learning & Project-based learning, case-studies, critical thinking technology. \\
\hline Person-centric approach & Technology of level differentiation. \\
\hline Research-based learning & $\begin{array}{l}\text { Involvement in research activities of all students in accordance } \\
\text { with their identified scientific interests; involvement of scientists } \\
\text { in the management of scientific activities of students; teaching } \\
\text { students to work with scientific literature, the development of a } \\
\text { culture of scientific research. }\end{array}$ \\
\hline Transparent educational system & \begin{tabular}{l} 
Expansion of the educational content due to the needs of students \\
\hline
\end{tabular}
\end{tabular}

\section{RESULTS}

The motives for the educational activity of students of medical and pedagogical universities are shown in Figure 1.

The educational activity of students of higher medical and pedagogical institutions is supported by numerous motives, that is, it is multi-motivated. A large number of motives increases the overall motivation to learn. In terms of the effect on motivation, the motives were not equal and were divided into stronger and weaker ones. Almost all students $(95.7 \%)$ had the strongest motive for becoming highly qualified specialists; thus, students are focused on developing their skills and becoming professionals (professional motive). The motive for acquiring deep and solid knowledge (89.4\%) indicates the influence of motivation on learning and mastering the educational program of the university (educational motive). The motive for ensuring the success of future professional activities was noted by $83.0 \%$ of respondents; thus, the student studies in order to become a

Figure 1. Students' motives for the choice of educational activities

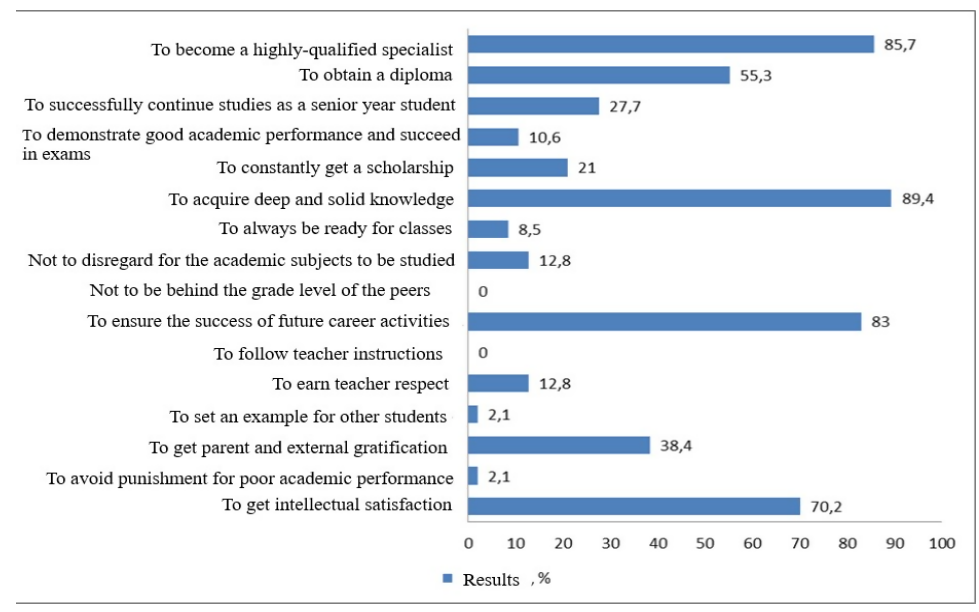


Table 4. Grouping of the motives for educational activities

\begin{tabular}{|l|l|l|}
\hline \multicolumn{1}{|c|}{ Groups of motives } & \multicolumn{1}{|c|}{ Motives } & \multicolumn{1}{c|}{ Result, \% } \\
\hline \multirow{3}{*}{ Intrinsic } & To become a highly-qualified specialist & 95.7 \\
\cline { 2 - 3 } & To acquire deep and solid knowledge & 89.4 \\
\cline { 2 - 3 } & To get intellectual satisfaction & 70.2 \\
\hline \multirow{2}{*}{ Extrinsic } & To ensure the success of future professional activities & 83.0 \\
\cline { 2 - 3 } & To get a diploma & 55.3 \\
\hline
\end{tabular}

professional (professional motive). The choice of the motive for getting intellectual satisfaction (70.2\%) demonstrated that it is important for students not only to gain knowledge but also to receive intellectual satisfaction from their development and search (cognitive motive, aesthetic). Fifty-five point three per cent of students find it important to get a diploma (professional and pragmatic motive). Being positively assessed by parents and close people is important for $38.4 \%$ of students (prestige motive). Such motives as keeping up with fellow students and fulfilling pedagogical requirements are not significant for students. Thus, among medical students, the dominant motives include professional, educational, and cognitive motives.

In the structure of motivation, the qualitative characteristic of motives in relation to the educational activity (extrinsic and intrinsic motives) is also very important. Extrinsic motivation is based on student rewards and punishments, the use of various external stimuli while learning is not important for the student. Intrinsic motivation is found in the inner world of the student personality, and the educational activity is a personal value; it is important as it satisfies the student's needs. Intrinsic motivation gives pleasure from work, promotes interest, and increases self-esteem. Student's interest in studies and a thirst for knowledge grow, first of all, due to intrinsic motivation. The structure of intrinsic and extrinsic motives of the educational activity of medical students is shown in Table 4.

The survey of students based on the methodology by T. I. Illyin (Motivation to study at university) involved the analysis of the three scales: Acquisition of knowledge (the desire to acquire knowledge, curiosity); Mastering the profession (the desire to acquire professional knowledge, to develop important professional qualities) and Obtaining a diploma (the desire to get a diploma based on formal assimilation of knowledge, the desire to find workarounds when taking exams and tests). The test results are shown in Table 5.

The students demonstrated average indicators on the Acquisition of knowledge and Mastering the profession Scale. The desire to obtain a diploma based on formal knowledge assimilation is also present among students but it does not dominate.

Motivation to avoid failure implies efforts not to achieve the goal, but to avoid possible defeats and losses; therefore, it is an ineffective strategy. Motivation to avoid failure is manifested by the lack of initiative, self-doubt, fear of criticism, and the choice of inadequate tasks. The focus of students on success rather than failure was assessed according to the given scale of the methodology. The motivation of medical students is described in Table 6.

Table 5. Motivation to learn of medical students, points

\begin{tabular}{|l|l|l|}
\hline \multicolumn{1}{|c|}{ Scale } & \multicolumn{1}{|c|}{ Student group value } & \multicolumn{1}{c|}{ Maximum value } \\
\hline Knowledge acquisition & 6.8 & 12.6 \\
\hline Mastering the profession & 5.6 & 10.0 \\
\hline Obtaining a diploma & 6.5 & 10.0 \\
\hline
\end{tabular}


Table 6. The motivation of medical students to succeed and avoid failure, points

\begin{tabular}{|l|l|l|}
\hline \multicolumn{1}{|c|}{ Motivation } & \multicolumn{1}{c|}{ Student motives } & \multicolumn{1}{c|}{ Motivational intensity } \\
\hline Achievement of success & 15.6 & Average $-11-16$ \\
\hline Failure avoidance & 17.7 & High $-17-20$ \\
\hline
\end{tabular}

Motivation to succeed is one of the psychological characteristics of students. It is at the average level (15.6 points), which shows that students have an average level of the need to achieve success and improve their performance. They are not very persistent to achieve their goals and improve selfesteem. Motivation to avoid failures (17.7 points) dominates among students. Fear of failure limits the academic activity and creativity of the student; it negatively affects self-esteem and hinders academic success. It has been established that the fear of failure increases personal anxiety and emotional imbalance, which also negatively affects the effectiveness of educational activities (Deryagina \& Sherstennikova, 2015).

Thus, the academic motivation of students of medical and pedagogical universities is supported by the complex interaction of intrinsic and extrinsic motives. Leading (strong) motives are aimed at future professional activities and mastering the knowledge needed. It is important that in the total number of motives there are pronounced intrinsic educational and cognitive motives, which indicate the desire of students to master new knowledge, search for knowledge, and study independently. In the context of medical education, the motives for avoiding failures dominate over the motives for achieving success, which can negatively affect the success of educational activities and indicates the need for psychological support for the development of the motivation to succeed in students.

The attitude of pedagogical students to personalized learning strategies in vocational education was defined based on the questionnaire described in Table 7.

The result of the first question was predictably high; $94 \%$ of respondents agreed that modern education is being changed. This indicates that students are aware of these changes as many of them

Table 7. A questionnaire about the attitude of pedagogical students to personalized learning strategies in vocational education

\begin{tabular}{|c|c|c|c|}
\hline \multirow[t]{2}{*}{ Question } & \multicolumn{3}{|c|}{ Result, \% } \\
\hline & Yes & No & Not sure \\
\hline 1. Do you agree that modern education has been dramatically changed? & 94 & 5 & 1 \\
\hline $\begin{array}{l}\text { 2. Do you think personalized learning in vocational education is a tool for } \\
\text { improving academic performance and student motivation? }\end{array}$ & 85 & 5 & 10 \\
\hline 3. Do you think that the desire to encourage self-education is a new trend? & 53 & 47 & - \\
\hline $\begin{array}{l}\text { 4. Do you think personalized learning strategies in vocational education are } \\
\text { related to the development of information technology? }\end{array}$ & 95 & - & 5 \\
\hline $\begin{array}{l}\text { 5. Do you think that the technology of critical thinking, case-studies, level } \\
\text { differentiation technology can be considered as personalized learning strategies? }\end{array}$ & 74 & 26 & - \\
\hline $\begin{array}{l}\text { 6. Do you think participation in scientific research can improve academic } \\
\text { performance and motivation to learn? }\end{array}$ & 68 & 22 & 10 \\
\hline $\begin{array}{l}\text { 7. Do you think that the introduction of curriculum projects into the learning } \\
\text { process will increase academic performance and motivation to learn? }\end{array}$ & 71 & 29 & - \\
\hline $\begin{array}{l}\text { 8. Do you agree that teachers use personalized learning strategies in your } \\
\text { institution? }\end{array}$ & 91 & 1 & 8 \\
\hline 9. Do you think that personalized learning strategies...? & & & \\
\hline
\end{tabular}




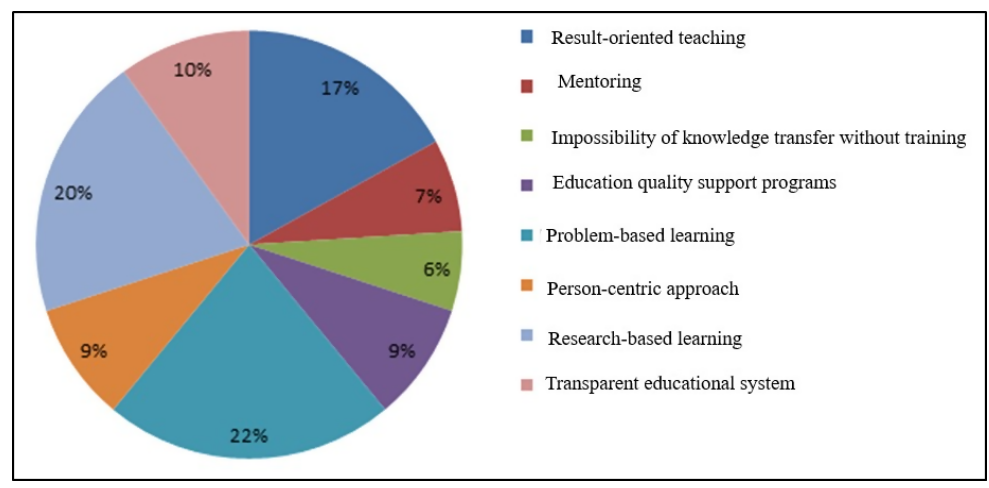

are directly related to the students themselves. The data on the second question also turned out to be high; $85 \%$ of respondents believe that in vocational education there is a need for an individual approach to train a specialist who can live in the given society and actively participate in its development, and who is also capable of self-development and self-realization. Surprisingly, the answers to the next question were almost equally divided $-53 \%$ of the students surveyed consider the promotion of selfeducation to be a modern trend, and $47 \%$ disagree with the statement. This result is probably due to the fact that self-education is not a new phenomenon for students.

The results of the next question showed that the respondents almost unanimously agreed (95\%) that the development of computer technology is associated with personalized learning strategies. This indicates that the respondents attribute the technological approach to self-education. The next question results also turned out to be high. Thus, $74 \%$ of respondents believe that technologies such as critical thinking, case-studies, and level differentiation are new trends in personalized learning strategies while $26 \%$ of respondents disagree with the statement due to the fact that these technologies can be defined as innovative technologies and problem-based learning. As for the sixth question, the data were surprisingly low. Only $68 \%$ of respondents agreed that scientific research will help increase academic performance and motivation to learn. This result can be justified by the fact that training in medical institutions involves spending a lot of time on preparing and completing educational assignments. A fairly large percentage of respondents (71\%) agreed that the introduction of educational projects in the learning process will increase academic performance and motivation to learn. When answering this question, the students were also asked to explain their views; $29 \%$ of those who disagreed could choose a negative answer due to their personal preferences. The majority of the respondents (91\%) indicated that personalized learning strategies are used to some extent in their educational institutions. It was not surprising as in almost any modern educational institution, personalized learning strategies are one of the approaches to professional training of specialists.

The analysis of the student survey was followed by the analysis of the teacher survey. The data obtained are described in the chart (Figure 2).

Thus, the most common responses were "problem-based learning" and "research-based learning". This may indicate that problem-based learning is currently one of the most famous and well-established teaching methods. The fairly high indicator of "research-based learning" shows that teachers believe that research lays the foundation for knowledge, skills, and abilities of the active, creative, and independent activity of students, methods of analysis, synthesis, and assessment of the results of their activities.

In addition, a number of teachers noted that it is important to "teach students to focus on the result" This suggests that higher education is not theoretical but aimed at obtaining practical knowledge. The "impossibility of knowledge transfer without training" and "mentoring" items were 
given the lowest assessments. This may be explained by the fact that many educators are trying to use innovative teaching methods.

\section{DISCUSSION}

The research on personalized learning strategies as a tool for enhancing academic achievement and student motivation has shown that in recent years, empirical researchers in the field of self-regulated learning have given a lot of attention to the strategic regulation of motivation. Studies by American scientists have reported the importance of the use of motivational regulation strategies in different contexts to achieve desired academic results (e.g. Park \& Jun, 2017; Smit et al., 2017). The study involved 141 undergraduate and graduate students enrolled in online courses. The results showed that students use different motivational regulation and cognitive learning strategies that are determined by their academic level. The hierarchical regression analysis with two dependent variables (i.e. superficial learning strategies and advanced learning strategies) showed that superficial learning strategies (i.e. rehearsal, repetition) and advanced learning strategies (i.e. development, organization, and critical thinking) involve different sets of motivational regulation strategies after the consideration of academic performance and age. In particular, the researchers at the Philipps University of Marburg, noted a positive impact of motivational regulation strategies on the academic efforts (for example, Schwinger \& Otterpohl, 2017; Smit et al., 2017) and academic performance of students (for example, Schwinger \& Otterpohl, 2017) in the context of higher education. The German researchers examined the relationship between the use of different motivational regulation strategies and the two important aspects of academic performance: academic performance and the intention to drop out. They provided additional evidence for the relevance of the introduction of motivational regulation strategies into curricula aimed at improving academic performance and preventing students from dropping out Kryshko et al. (2020).

Problem-based learning as one of the models of personalized learning strategies was highly appreciated by the teachers surveyed in our study. Indonesian scientists studied the impact of ProblemBased Learning (PBL), the Predict, Observe, Explan (POE) methodology and their combination (PBLPOE) on critical thinking skills and students' scientific attitude to biology. The study relied on a non-equivalent pre- and post-test control group of 132 students from Bengkulu, Indonesia. This study was conducted from February to June 2018. An essay test was conducted to assess the critical thinking skills of the participants; there was also a checklist and an interview guide to observe students' scientific attitudes. The highest post-test score was obtained in the PBLPOE group. Thus, PBLPOE can be used to improve student performance in biology. Thus, PBLPOE is an effective teaching method that improves student performance (Apriza et al., 2020).

The improvement of students' creative thinking skills plays an important role in the modern learning theory. This is confirmed by the study devoted to the determination of the effectiveness of teaching creative entrepreneurship based on the skills of discovery (CEL-BaDiS) for improving creative thinking skills of students. The conceptual model (CEL-BaDiS) is created based on the review and discussion at a colloquium prior to the peer review and testing phase. The CEL-BaDiS model involves 6 learning stages, namely association, questioning, observation, experimentation, communication through posters, and networking with persuasion. Learning is systematical and incremental, which facilitates the interaction between students, as well as between students and teachers in the learning process. In the model, the lecturer acts as a facilitator and motivator. The teacher presents facts and examples, which are updated via video or directly on the Internet. Thus, the teacher motivates students to ask questions and argue about the phenomenon the lecturer is talking about. The research results showed that the average score of the expert group was higher than that of the existing group. This demonstrates the effectiveness of the model for the development of creative thinking in the aspects of flexibility, fluency, originality and elaboration (Sajidan et al., 2020).

It should be noted that personalized learning has existed for hundreds of years in the form of apprenticeship and mentoring. In a number of research circles, learning has been characterized 
as a steady and constant change in personal knowledge and abilities. Personalized learning is an integrated approach to activities that are the product of self-organization or learning, or the individual instruction that takes into account personal needs and goals. Personalized learning can become an effective approach that can increase motivation, engagement and understanding, as well as enhance student satisfaction and the efficiency of learning (Shemshack \& Spector, 2020). A good example of personalized learning is project-based learning, which provides students with opportunities to actively develop their knowledge and solve a problem through product manufacturing activities. The learning model allows students to develop their academic qualities such as honesty, responsibility, and the ability to communicate and accept criticism and suggestions from others. Project assignments encourage students to independently search for references in the learning process and contribute to deeper assimilation of the educational material which is associated with real life experience. This is evidenced by a study showing that project-based learning has a positive effect on academic performance in science compared to traditional education; it effectively reduces academic procrastination and provides more opportunities for better learning outcomes (Santyasa et al., 2020).

Today, in the 21 st century, the learning process is integral to the digital environment. A digital learning environment is classified as a personalized learning environment that is tailored to individual knowledge, experience, interests, and the promotion of expected learning outcomes. A special approach to the implementation of personalization is the approach of multilevel electronic tasks, which take into account the individual characteristics of the student (Al Kandari et al., 2020). In addition, effective personalized learning can increase student motivation and participation in learning activities contributing to better learning outcomes. Thus, providing the same assignment content to students with different qualifications and personal qualities, as well as with different interests and needs is no longer considered adequate as learning can now be personalized. Today personalized learning is considered as a solution to adapt learning in accordance with the needs of students and their previous experience in order to enable everyone to unfold their maximum potential through personalized learning. Personalized learning is in demand due to new technologies that include big data and learning analytics. The learning environment must be adapted and constantly evolving according to the conditions, abilities, preferences, basic knowledge, interests and goals of the learner; it should also be adjusted to the evolving skills and knowledge of the learner. Personalized learning is a tool that promotes student-centered learning (Bahçeci \& Gürol, 2016). Swiss scientists presented a modern model of the use of digital technologies for personalized learning. The widespread use of digital technologies in the learning environment characterized by open learning methods is an important aspect of personalized learning as it positively affects both the assessment of digital skills and ICT-related beliefs by learners (Schmid \& Petko, 2019).

Adaptive learning, blended learning, differentiation, individual instruction, individual learning path, personalized educational program, proactive support, real-world connections are the hallmarks of personalized learning. In general, personalized learning models strive to adapt to the pace of learning and learning strategies, as well as to the content and activities used in order to best fit the strengths, weaknesses and interests of each student. Personalized learning encourages students to manage their learning experience through differentiated instruction and personalized real-time teacher and student feedback that are mixed throughout the learning process (Bahçeci \& Gürol, 2016). The purpose of the study by Turkish scientists was to examine the change in self-efficacy when making career decisions during the course of Career planning in the transition to business life at the state university in Ankara. Individual assignments used at the practical lessons contributed to the correct assessment of selfefficacy when making decisions (Aka, 2020). Modern pedagogical analytics can ensure the process of content personalization, which will allow identifying student characteristics and linking them to the learning model. In addition, the ability to reactively organize personalized content, which will be a beneficial factor in promoting support for learning in a virtual learning environment with a focus on different student characteristics, preferences, and complexity factors (Bahçeci \& Gürol, 2016). 


\section{CONCLUSION}

The data obtained as a result of the content analysis and methodological triangulation confirmed the positive impact of personalized learning strategies on academic performance and student motivation to learn. Personalized learning approaches have proved to be effective teaching and learning methods for medical students. The study focuses on the opinions of both students and teachers, special surveys were conducted for both these groups. Students believe that personalized learning in vocational education is a tool for enhancing academic achievement and motivation and highly assessed modern methods of personalized learning strategies: critical thinking technology, case-studies, level differentiation technology, project-based learning, etc. This model increases the intrinsic motivation of students, ensures satisfaction from learning, arouses interest, improves self-esteem, which has been confirmed by the survey data. The opinions of educators and students simultaneously emphasized the importance of use separate components of personalized learning strategies: reflection on teaching style and find practical solutions to overcome the misconceptions or problems that students have while studying a particular discipline. A number of teachers consider personalized learning strategies as a way to improve traditional learning styles and increase student engagement, achievement and motivation. The study encourages the integration of different approaches of personalized strategies, which has been confirmed by the results of the questionnaire.

Based on the results of a survey of students and teachers in order to expand the use of individual strategies in vocational education, it is recommended:

- $\quad$ to get acquainted with the structure and goals of a particular educational institution;

- to analyze the curricula and the courses provided, which will determine the use of personalized strategies;

- $\quad$ to develop guidelines for the implementation and application of personalized strategies;

- to choose the method of personalized strategies, to develop individual tasks, to conduct classes based on personalized learning strategies.

The findings of the study allow us to implement personalized learning strategies that are most highly rated by students and teachers at the same time, as well as highlight a number of other important behavioral factors that must be taken into account when introducing methods of personalizing education. It should be highlighted that there is a need to create a model of personalized learning strategies that will include a variety of teaching methods. The approbation of the model will make it possible to more thoroughly study the changes in students' attitudes towards learning, the acquisition of practical knowledge and skills. Moreover, the approbation should be carried out based on more complex methods of statistical data analysis. In addition, a similar study can be carried out among citizens of other countries. The research results can be used as a basis for conducting other surveys or comparison with the statistical data for different years.

Future studies continuing to develop the results obtained now should focus on the relationship and correlation of student motivation and their results when applying personalized learning strategies using intelligent learning systems; the role of the teacher in the interaction of students with intelligent systems is also of critical interest.

\section{Recommendations}

Based on the results obtained, it is recommended to use the methods and techniques of personalized learning, primarily in vocational education. The best choice is not to use isolated personalization methods, but to extend this approach to all aspects of student learning; it is necessary to generate continuous feedback from students to confirm student motivation and opportunities for higher academic results. 


\section{REFERENCES}

Afini Normadhi, N. B., Shuib, L., Md Nasir, H. N., Bimba, A., Idris, N., \& Balakrishnan, V. (2019). Identification of personal traits in adaptive learning environment: Systematic literature review. Computers \& Education, 130, 168-190. doi:10.1016/j.compedu.2018.11.005

Aka, E. I. (2020). Investigating the change in career decision making self-efficacy levels of university students. International Journal of Curriculum and Instruction, 12(1), 310-326.

Al Kandari, M. M., Ali, M., Al Qattan, M. M., \& Mousa, M. (2020). E-task-based learning approach to enhancing 21st-century learning outcomes. International Journal of Instruction, 13(1), 551-566. doi:10.29333/iji.2020.13136a

Alyami, M., Melyani, Z., Johani, A. A., Ullah, E., Alyami, H., Sundram, F., Hill, A., \& Henning, M. (2017). The impact of self-esteem, academic self-efficacy and perceived stress on academic performance: A cross-sectional study of Saudi psychology students. European Journal of Educational Sciences, 4(3), 51-63. doi:10.19044/ejes.v4no3a5

Apriza, F., Siti, Z., Herawati, S., Muhdhar, A., \& Irawati, M. H. (2020). PBLPOE: A learning model to enhance students' critical thinking skills and scientific attitudes. International Journal of Instruction, 13(2), 89-106. doi:10.29333/iji.2020.1327a

Artino, A. R., La Rochelle, J. S., \& Durning, S. J. (2010). Second-year medical students' motivational beliefs, emotions, and achievement. Medical Education, 44(12), 1203-1212. doi:10.1111/j.1365-2923.2010.03712.x PMID:21091760

Bahçeci, F., \& Gürol, M. (2016). The effect of individualized instruction system on the academic achievement scores of students. Education Research International, 2016, 1-9. doi:10.1155/2016/7392125

Chan, C., Hart, A., Lister, A., \& Doyle, S. (2011). Learning styles of 3rd year genetics students and their affection and perception of effectiveness of a range of instructional modes. Proceedings of the Australian Conference on Science and Mathematics Education (Formerly UniServe Science Conference), 7, 62-68.

Chatti, M. A., Jarke, M., \& Specht, M. (2010). The 3P learning model. Journal of Educational Technology \& Society, 13(4), 74-85.

Coffield, F., Moseley, D., Hall, E., \& Ecclestone, K. (2004). Learning styles and pedagogy in post-16 learning: A systematic and critical review. Learning and Skills Research Centre.

Cohen, A. D. (2011). Strategies in learning and using a second language. Routledge.

Deryagina, L. E., \& Sherstennikova, A. K. (2015). The role of dominant motivation in the success (failure) of educational activity and its relationship with personal and situational anxiety. Modern Research on Social Problems, 12(56), 3-14. doi:10.12731/2218-7405-2015-12-1

Edgar, S., Carr, S. E., Connaughton, J., \& Celenza, A. (2019). Student motivation to learn: Is self-belief the key to transition and first year performance in an undergraduate health professions program? BMC Medical Education, 19(1), 111. doi:10.1186/s12909-019-1539-5 PMID:30999916

Ehlers, T. (n.d.). Motivation to succeed and motivation to avoid failure. https://psycabi.net/testy/272-metodikadiagnostiki-lichnosti-na-motivatsiyu-k-izbeganiyu-neudach-t-elersa-oprosnik-t-elersa-dlya-izucheniya-motivatsiiizbeganiya-neudach

Erstad, O., \& Voogt, J. (2018). The twenty-first century curriculum: issues and challenges. In Springer International Handbooks of Education (pp. 19-36). Springer. doi:10.1007/978-3-319-71054-9_1

Eseryel, D., Law, V., Ifenthaler, D., Ge, X., \& Miller, R. (2014). An investigation of the interrelationships between motivation, engagement, and complex problem solving in game-based learning. Journal of Educational Technology \& Society, 17(1), 42-53.

Felder, R. M., \& Silverman, L. K. (1988). Learning and teaching styles in engineering education. Engineering Education, 78(7), 674-681.

Gómez, S., Zervas, P., Sampson, D. G., \& Fabregat, R. (2014). Context-aware adaptive and personalized mobile learning delivery supported by UoLmP. Journal of King Saud University - Computer and Information Sciences, 26(1), 47-61. .10.1016/j.jksuci.2013.10.008 
Hachfeld, A., \& Lazarides, R. (2020). The relation between teacher self-reported individualization and studentperceived teaching quality in linguistically heterogeneous classes: An exploratory study. European Journal of Psychology of Education. Advance online publication. doi:10.1007/s10212-020-00501-5

Hayat, A. A., Shateri, K., Amini, M., \& Shokrpour, N. (2020). Relationships between academic self-efficacy, learning-related emotions, and metacognitive learning strategies with academic performance in medical students: A structural equation model. BMC Medical Education, 20(1), 76. doi:10.1186/s12909-020-01995-9 PMID:32183804

Hernández-Torrano, D., Ali, S., \& Chan, C. K. (2017). First year medical students' learning style preferences and their correlation with performance in different subjects within the medical course. BMC Medical Education, 17(1), 131. doi:10.1186/s12909-017-0965-5 PMID:28789690

Hsieh, C. W., \& Chen, S. Y. (2016). A cognitive style perspective to handheld devices: Customization vs. personalization. International Review of Research in Open and Distance Learning, 17(1), 1-22. doi:10.19173/ irrodl.v17i1.2168

Ilyin, E. P. (2011). Motivation and motives. Peter.

Kryshko, O., Fleischer, J., Waldeyer, J., Wirth, J., \& Leutner, D. (2020). Do motivational regulation strategies contribute to university students' academic success? Learning and Individual Differences, 82, 101912. doi:10.1016/j. lindif.2020.101912

Lee, D., Huh, Y., Lin, C. Y., \& Reigeluth, C. M. (2018). Technology functions for personalized learning in learner-centered schools. Educational Technology Research and Development, 66(5), 1269-1302. doi:10.1007/ s11423-018-9615-9

Lehmann, T., Hähnlein, I., \& Ifenthaler, D. (2014). Cognitive, metacognitive and motivational perspectives on preflection in self-regulated online learning. Computers in Human Behavior, 32, 313-323. doi:10.1016/j. chb.2013.07.051

Lin, C. F., Yeh, Y. C., Hung, Y. H., \& Chang, R. I. (2013). Data mining for providing a personalized learning path in creativity: An application of decision trees. Computers \& Education, 68, 199-210. doi:10.1016/j. compedu.2013.05.009

Lu, C., Chang, M. K., Huang, E., \& Chen, C. W. (2014). Context-aware mobile role-playing game for learning. In The new development of technology enhanced learning. Lecture notes in educational technology (pp. 131-146). Springer. doi:10.1007/978-3-642-38291-8_8

Malykhin, O., \& Galla, A. O. (2016). The phenomenon of learning styles in the professional training of philology students. Bulletin of Chernihiv National Pedagogical University. Series. Pedagogical Sciences, 133, 120-123.

Mega, C., Ronconi, L., \& De Beni, R. (2014). What makes a good student? How emotions, self-regulated learning, and motivation contribute to academic achievement. Journal of Educational Psychology, 106(1), 121-131. doi:10.1037/a0033546

Miliband, D. (2006). Choice and voice in personalised learning. In OECD (Ed.), Schooling for tomorrow: Personalising education (pp. 21-30). OECD Publishing. doi:10.1787/9789264036604-2-en

Moos, D. C., \& Bonde, C. (2016). Flipping the classroom: Embedding self-regulated learning prompts in videos. Technology. Knowledge and Learning, 21(2), 225-242. doi:10.1007/s10758-015-9269-1

Morgan, B., Hogan, A. M., Hampton, D., Lippert, A., \& Graesser, A. C. (2020). The need for personalized learning and the potential of intelligent tutoring systems. In Handbook of learning from multiple representations and perspectives (pp. 1-37). Routledge. doi:10.4324/9780429443961-32

Mousavinasab, E., Zarifsanaiey, N., \& Niakan Kalhori, R.,, S., Rakhshan, M., Keikha, L., \& Ghazi Saeedi, M. (2018). Intelligent tutoring systems: A systematic review of characteristics, applications, and evaluation methods. Interactive Learning Environments, 29(1), 142-163. doi:10.1080/10494820.2018.1558257

Ngwira, F. F., Gu, C., Mapoma, H. W. T., \& Kondowe, W. (2017). The role of academic emotions on medical and allied health students' motivated self-regulated learning strategies. Journal of Contemporary Medical Education, 5(1), 23-30. doi: $10.5455 /$ jcme.20170412124640

Park, S., \& Jun, H. (2017). Relationships between motivational strategies and cognitive learning in distance education courses. Distance Education, 38(3), 302-320. doi:10.1080/01587919.2017.1369007 
Pontual Falcão, T., Mendes de Andrade e Peres, F., Sales de Morais, D. C., \& da Silva Oliveira, G. (2018). Participatory methodologies to promote student engagement in the development of educational digital games. Computers \& Education, 116, 161-175. doi:10.1016/j.compedu.2017.09.006

Rodríguez-Triana, M. J., Martínez-Monés, A., Asensio-Pérez, J. I., \& Dimitriadis, Y. (2015). Scripting and monitoring meet each other: Aligning learning analytics and learning design to support teachers in orchestrating CSCL situations. British Journal of Educational Technology, 46(2), 330-343. doi:10.1111/bjet.12198

Sagheb, M. M., Amini, M., Saber, M., Moghadami, M., Nabiei, P., Khalili, R., Rezaee, R., Bazrafcan, L., \& Hayat, A. A. (2018). Teaching Evidence-Based Medicine (EBM) to undergraduate medical students through flipped classroom approach. Shiraz E Medical Journal, 19(2), 1-6. doi:10.5812/semj.57150

Sajidan, M., Saputro, S., Perdana, R., Atmojo, I. R. W., \& Nugraha, D. A. (2020). Development of science learning model towards Society 5.0: A conceptual model. Journal of Physics: Conference Series, 1511, 012124. doi:10.1088/1742-6596/1511/1/012124

Samarakoon, L., Fernando, T., Rodrigo, C., \& Rajapakse, S. (2013). Learning styles and approaches to learning among medical undergraduates and postgraduates. BMC Medical Education, 13(1), 42. doi:10.1186/1472-692013-42 PMID:23521845

Santyasa, I. W., Rapi, N. K., \& Sara, I. W. W. (2020). Project based learning and academic procrastination of students in learning physics. International Journal of Instruction, 13(1), 489-508. doi:10.29333/iji.2020.13132a

Scheiter, K., Schubert, C., Schüler, A., Schmidt, H., Zimmermann, G., Wassermann, B., Krebs, M.-C., \& Eder, T. (2019). Adaptive multimedia: Using gaze-contingent instructional guidance to provide personalized processing support. Computers \& Education, 139, 31-47. doi:10.1016/j.compedu.2019.05.005

Schmid, R., \& Petko, D. (2019). Does the use of educational technology in personalized learning environments correlate with self-reported digital skills and beliefs of secondary-school students? Computers \& Education, 136, 75-86. doi:10.1016/j.compedu.2019.03.006

Schumacher, C., \& Ifenthaler, D. (2018). The importance of students' motivational dispositions for designing learning analytics. Journal of Computing in Higher Education, 30(3), 599-619. doi:10.1007/s12528-018-9188-y

Schwinger, M., \& Otterpohl, N. (2017). Which one works best? Considering the relative importance of motivational regulation strategies. Learning and Individual Differences, 53, 122-132. doi:10.1016/j.lindif.2016.12.003

Shemshack, A., \& Spector, J. M. (2020). A systematic literature review of personalized learning terms. Smart Learning Environments, 7(1), 33. doi:10.1186/s40561-020-00140-9

Smit, K., de Brabander, C. J., Boekaerts, M., \& Martens, R. L. (2017). The self-regulation of motivation: Motivational strategies as mediator between motivational beliefs and engagement for learning. International Journal of Educational Research, 82, 124-134. doi:10.1016/j.ijer.2017.01.006

Tapalova, O. B. (2014). Achievement motivation as an internal factor of student's personality development. Literacy Information and Computer Education Journal, 5(1), 1408-1412. doi:10.20533/licej.2040.2589.2014.0200

Tapalova, O. B., Kalipanova, M. K., \& Amanzhanova, G. B. (2018). Correlation of the indicators of the need for achievement with personal factors in the group of students and managers. Bulletin of KazNU Al-Farabi. Series of Psychology and Sociology, 64(1), 26-37. doi:10.26577/JPSS-2018-1-615

Wang, Y. H., \& Liao, H. C. (2011). Adaptive learning for ESL based on computation. British Journal of Educational Technology, 42(1), 66-87. doi:10.1111/j.1467-8535.2009.00981.x

Witkin, H. A., Dyk, R. B., Fattuson, H. F., Goodenough, D. R., \& Karp, S. A. (1962). Psychological differentiation: Studies of development. Wiley. doi:10.1037/13128-000

Yang, J., \& Zhang, B. (2019). Artificial intelligence in intelligent tutoring Robots: A systematic review and design guidelines. Applied Sciences (Basel, Switzerland), 9(10), 2078. doi:10.3390/app9102078 
Aliya Makhambetova is a Doctoral Student of the Department of Special Education at the Abai Kazakh National Pedagogical University, Almaty, Kazakhstan.

Nadezhda Zhiyenbayeva, Ph.D., is a Professor of the Department of Special Education at the Abai Kazakh National Pedagogical University, Almaty, Kazakhstan.

Elena Ergesheva, Ph.D., is an Associate Professor of the Department of Propaedeutics of Dental Diseases of the Institute of Dentistry at the I.M. Sechenov First Moscow State Medical University (Sechenov University), Moscow, Russia. 